\title{
Subject gaps in German coordinative structures - Empirical evidence for a gradient phenomenon
}

Petra-Kristin Bonitz, Anke Holler

Department of German Studies, University of Goettingen, Germany

https://doi.org/10.36505/ExLing-2011/04/0008/000177

\begin{abstract}
In this article we investigate German complex clauses containing a subject gap using the empirical method of Magnitude Estimation. We will present evidence for the fact that subject gaps in coordinative structures can be characterized by (i) gradience and (ii) regional distinctiveness. Against the background of the recent critical discussion of Magnitude Estimation (e.g. Featherston 2008), we show that this method qualifies to test hierarchical graduation of acceptability.
\end{abstract}

Keywords: magnitude estimation, ellipsis, coordination, gradience, descriptive grammar of German

\section{Phenomenon}

The focus of our study lies on German complex coordinated clauses containing a subject gap as exemplified in (1).

$\begin{array}{llll}\text { (1) Wahrscheinlich } & \text { geht Tino in die Kneipe und } \\ \text { Likely } & \text { goes Tino } & \text { into a pub } & \text { and } \\ \text { bestellt } & \text { ein großes Bier. } & \\ \text { orders a } & \text { large beer. }\end{array}$

'Tino probably goes into a pub and orders a large beer.'

It is usually assumed that this phenomenon, called SLF ${ }^{1}$-coordination (Höhle 1983), has the following characteristics: (i) inversion at the first conjunct; (ii) subject gap (ellipsis) in the second conjunct; (iii) finite verb under $\mathrm{C}^{\circ}$ by symmetric coordination (finite-frontal) or even asymmetric coordination (cf. Reich 2009). Thus, the linear structure of examples like (1) can be simplified in the following way (with 'e' marking a gap):
(2) a. prefield
$\mathrm{V}_{\text {fin }} \mathrm{NP}_{\mathrm{Nom}}[\ldots]$ and $\mathrm{e} \mathrm{V}_{\text {fin }}$
$[\ldots]$
b. prefield
$\mathrm{V}_{\text {fin }} \mathrm{NP}_{\mathrm{Nom}}[\ldots]$ and $\mathrm{e} \mathrm{V}_{\text {fin }}$
e $[\ldots]$

Both the acceptability of coordinate constructions like (1) and their theoretical status are still under debate. The more normatively oriented Duden grammar (2009), for instance, only gives a tendential judgement about the preference of these structures (with or without the subject in the second conjunct). In contrast, different analysis of SLF-coordination, for example concerning the correct localization of the subject gap, have been proposed in the grammar-theoretical literature: Either the gap has been taken

ExLing 2011: Proceedings of 4th Tutorial and Research Workshop on Experimental Linguistics, 25-27 May, Paris, France 
to be located before the finite verb under SpecCP like in (2a) (cf. amongst others Fanselow 1991) or after the finite verb like in (2b) where the first gap marks the empty prefield (cf. amongst others Hartmann 1994). However, a comprehensive empirical assessment of SLF-coordination that makes predictions for an adequate modeling of the phenomenon is still outstanding.

The empirical data we present here allow a broad evaluation of the acceptability of SLF-coordination as well as of the proposed theoretical analysis to account for this phenomenon. We will show that SLFcoordination is a gradual and regionally variant grammatical phenomenon, which fact explains the wide spectrum of asserted judgements and theoretical accounts.

\section{Method}

Although there are many possible methods to collect data about linguistic structures such as corpus data, reaction time measurements, eye tracking, etc., we employed an opinion survey via Magnitude Estimation (ME) (Cowart 1997, McGee 2003) because of the advantages of this method for clarifying our specific problem. The supposed gradience and regional distinctiveness of SLF-coordination can be well detected with ME since this method is able to provide a hierarchical graduation of the acceptability of clause structures (see among others Bard et al. 1996, Schütze 1996). The merit of ME lies in the fact that one does not need a pre-defined scale, like a 5- or 7-point scale, which is limited by its very nature. With this method the test persons create their own magnitude scale by estimating sentences relative to each other so that even small differences in the acceptability of structures are documented.

The study has been realized as an online survey with 623 probands that had to judge the acceptability of stimuli of the following kind:

(3) Vielleicht fuhr [die Frau] in die Stadt und

Maybe drives [the woman ${ }_{\mathrm{NOM}}$ ] into the town and

[die Frau] besuchte Freunde.

[the woman ${ }_{\mathrm{NOM}}$ ] visits friends.

'Perhaps the woman drove into town and the woman visited some friends.'

We developed a systematic pattern that consists of eight scenarios which all share the same sentence types. These types were established in the way that the $\mathrm{NP}_{\mathrm{NOM}}$ in the first and/or the second conjunct was manipulated so that 13 different conditions in each scenario emerged. The test subjects were German native speakers from Germany, Austria and Switzerland. 


\section{Results and discussion}

By means of the collected data we argue that there is a linear distribution in the acceptability of complex clauses with realized subjects in both conjuncts versus complex clauses with a subject ellipsis in the second conjunct.

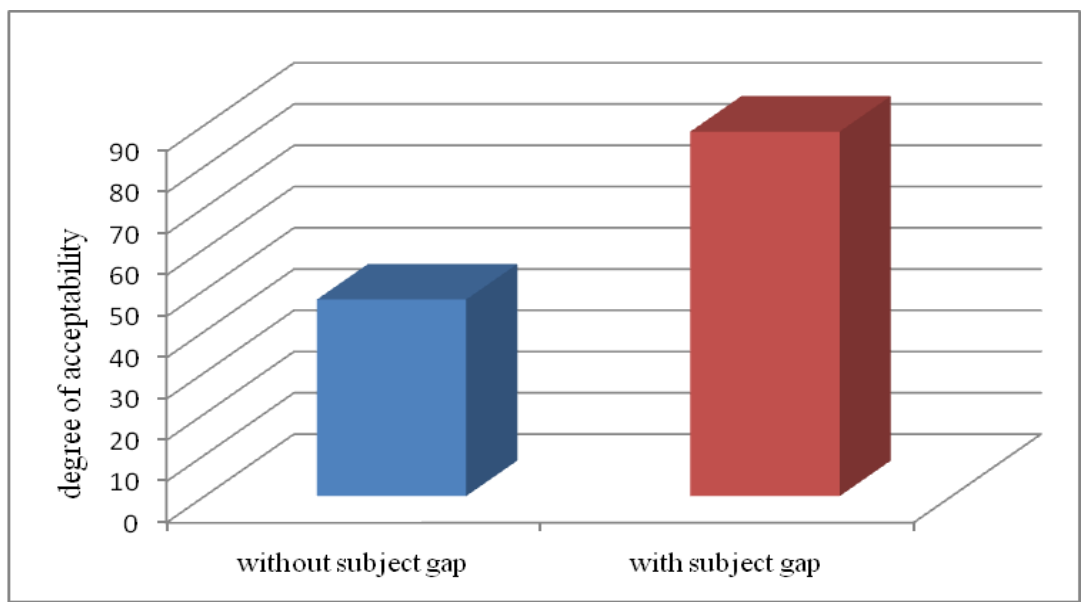

Figure 1. Distribution of the preferences.

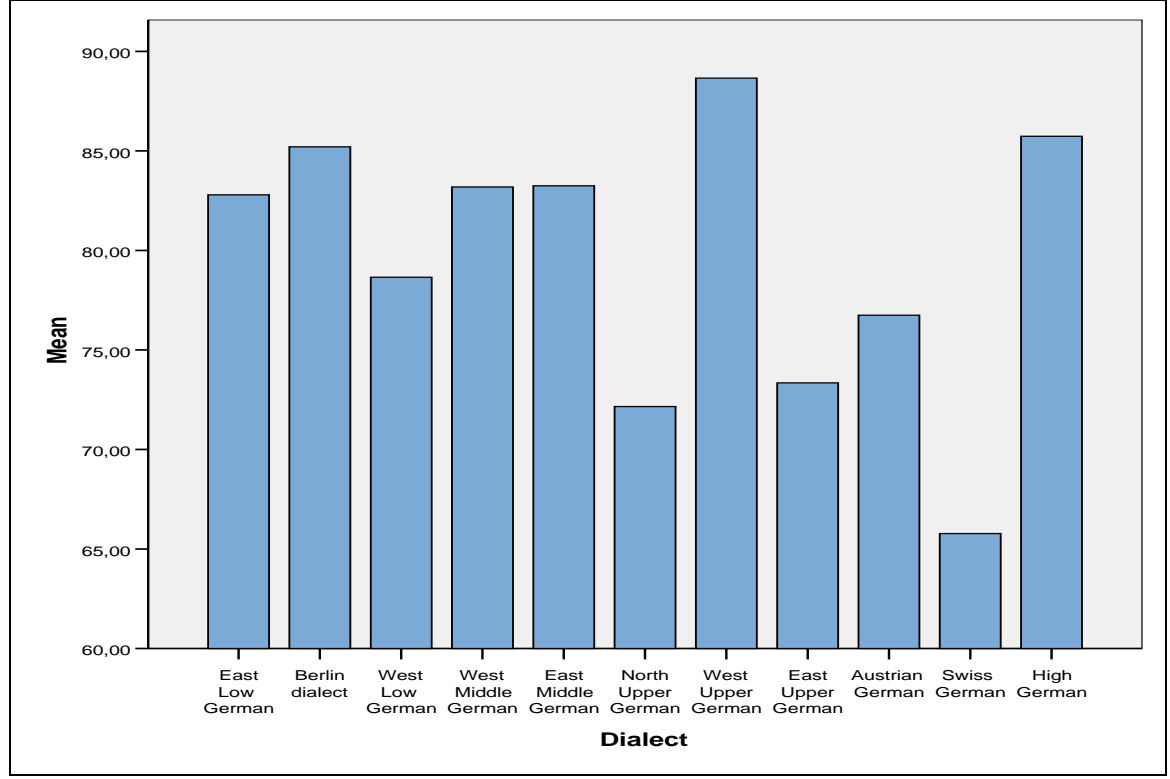

Figure 2. Regional effects. 
Our results prove that subject ellipses are significantly preferred, which was shown by a T-test $(t(622)=17.17, p<.05)$ (cf. figure 1$)$. This is contradictory to the assumptions in the normative German grammar (e.g. Duden 2009). By analyzing the data more specifically effects become obvious that give evidence for (i) gradual dependencies and (ii) differences throughout the regional German dialects. There are several conditions, such as the substitution of the noun phrase with a personal pronoun or an indefinite pronoun, that altogether support the gradual character of SLFcoordination. Its regional distinctiveness follows from observed regional differences. As is visualized in figure 2, test persons from the northern German speaking regions judge the elliptical construction better than test persons from the southern German speaking regions (especially the Swiss German). Because of the gradual and additionally regional dependent character of the SLF-coordination existing grammatical theoretical approaches have to be revised.

\section{Summary}

Crucial for the descriptive grammar is our result that empirical data show differences in the acceptability of German SLF-coordination. These structures can be characterized by gradience and regional distinctiveness.

\section{Notes}

1. Subjektlücke in finit-frontalen Sätzen (subject gap in finite-frontal sentences)

\section{References}

Bard, E.G., Robertson, D., Sorace, A. 1996. Magnitude Estimation of Linguistic Acceptability. Language 72, No.1, 32-68.

Cowart, W. 1997. Experimental Syntax. Applying Objective Methods to Sentence Judgments. Thousand Oaks etc.: Sage.

Dudenredaktion (ed.) 2009. Duden. Die Grammatik. ${ }^{8}$ Mannheim u.a., Dudenverlag.

Fanselow, G. 1990. Minimale Syntax. GAGL 32.

Featherston, S. 2008. Thermometer judgements as linguistic evidence. In Riehl, C. and Rothe, A. (eds.) Was ist linguistische Evidenz?, 69-89. Aachen, Shaker.

Hartmann, K. 1994. Zur Koordination von V-2 Sätzen. Zeitschrift für Sprachwissenschaft 13, 3-19.

Höhle, T. N. 1983. Subjektlücken in Koordinationen. (www.linguistik.uni-tuebingen.de/hoehle/manuskripte/SLF-W5.1_neu.pdf).

McGee, M. 2003. Usability Magnitude Estimation. In Proceedings of the Human Factors and Ergonomics Society 47 ${ }^{\text {th }}$ Annual Meeting, 691-695.

Reich, I. 2009. Asymmetrische Koordination im Deutschen. Tübingen, Stauffenburg.

Schütze, C. T. 1996. The Empirical Base of Linguistics. Grammaticality Judgments and Linguistic Methodology. Chicago/ London, University of Chicago Press. 